\title{
> Rubem Fonseca: da moldura à ekphrasis
}

> Rubem Fonseca: from frame to ekphrasis

\section{por Murilo Eduardo dos Reis}

Doutorando em Estudos Literários na linha de pesquisa Teorias e Crítica da Narrativa do Programa de Pós-graduação em Estudos Literários da Universidade Estadual Paulista "Júlio de Mesquita Filho" (UNESP), com bolsa Capes. E-mail: muriloreis86@gmail.com. ORCID: 0000-0001-5372-4326.

\section{Resumo}

O tema do artigo são as representações de moldura e ekphrasis em A santa de Schöneberg, conto de Rubem Fonseca que tem como centro a vida e a obra do pintor Egon Schiele. O objetivo é verificar como tais procedimentos são realizados pelo narrador e de que maneira eles contribuem para o desenvolvimento da trama. Assim, tomamos como apoio teórico textos de estudiosos que tratam de moldura, da ekphrasis, da obra fonsequiana e de aspectos das narrativas breves, tais como Ortega y Gasset (1963), Rosana de Lima Soares (2001), João Adolfo Hansen (2006), Ariovaldo José Vidal (2000), e Ricardo Piglia (2004).

Palavras-chave: Rubem Fonseca. Moldura. Ekphrasis. Conto.

\begin{abstract}
The theme of the article is the representations of frame and ekphrasis in A santa de Schöneberg, a short story by Rubem Fonseca which focuses on the life and work of painter Egon Schiele. The objective is to verify how such procedures are performed by the narrator and how they contribute to the plot development. Thus, we take as theoretical support critical and analytical texts by scholars who deal with framing, the ekphrasis, Rubem Fonseca's work and aspects of short stories, such as Ortega y Gasset (1963), Rosana de Lima Soares (2001), João Adolfo Hansen (2006), Ariovaldo José Vidal (2000) and Ricardo Piglia (2004).
\end{abstract}

Keywords: Rubem Fonseca. Frame. Ekphrasis. Short story. 


\section{Introdução}

Segundo Ariovaldo José Vidal, os narradores de Rubem Fonseca são obcecados pelo substantivo preciso e pelo adjetivo cortante. ${ }^{1} \mathrm{O}$ mesmo crítico ainda afirma que, desde a publicação de seus primeiros contos, o escritor demonstrou forte influência da literatura policial de Raymond Chandler, sendo a imagem precisa - marca registrada de toda a sua obra - uma das mais acentuadas características dessa relação. ${ }^{2}$

Tânia Pellegrini vai mais além e compara a narrativa fonsequiana à fotografia, manifestação artística em que cada aspecto é imprescindível para a composição imagética. Ela enfatiza que, no gênero policial, o espaço se organiza de acordo com o modelo de representação realista, no qual os pormenores são realçados na montagem de um conjunto que não pode ter sua verossimilhança questionada. $^{3}$

A precisão verbal também aproxima a literatura de Fonseca do cinema. Em reportagem publicada na revista Bravo!, Tiago Petrik, Malu Porto e João Gabriel de Lima relatam que Rubem Fonseca foi muito influenciado pela linguagem das câmeras - ele só não teria optado por fazer filmes porque, ainda adolescente, ganhou uma máquina de escrever. Além disso, o autor costuma participar das adaptações fílmicas e televisivas de seus livros - casos de Bufo \& Spallanzani e Agosto, respectivamente. ${ }^{4}$

\footnotetext{
${ }^{1}$ Ariovaldo José Vidal, Roteiro para um narrador: uma leitura dos contos de Rubem Fonseca, 2000, p. 91.

${ }^{2}$ Ibidem, p. 75.

${ }^{3}$ Tânia Pellegrini, "Rubem Fonseca", 1999, p. 98.

${ }^{4}$ Tiago Petrik, Malu Porto e João Gabriel de Lima, "O personagem Rubem Fonseca", 2009, p. 3435.
} 
Vale destacar que também são de sua autoria dois livros relacionados ao tema da transposição da literatura para a película: Vastas emoções e pensamentos imperfeitos e $O$ selvagem da ópera - o primeiro, romance protagonizado por um diretor que tenta fazer versão da obra $O$ exército da cavalaria, de Bábel; o segundo, argumento cinematográfico que aborda a biografia de Carlos Gomes.

Ainda reforçando a afinidade do escritor com a sétima arte, os autores da matéria dizem que ele trabalhou como roteirista de filmes publicitários do Instituto de Pesquisas e Estudos Sociais (IPES), órgão fundado em 1962 que buscava lançar ideias liberais e antimarxistas - informação da professora Aline Andrade Pereira, autora da tese $O$ verdadeiro Mandrake: Rubem Fonseca e sua onipresença invisível (1962-1989), entrevistada pelos jornalistas. ${ }^{5}$

Evidenciando a forte ligação do cinema com o estilo policialesco adotado por Fonseca, Sebastião Uchoa Leite escreve que filmes baseados em romances policiais tendem a obter mais sucesso na transposição de suportes, pois suas fontes originais se propõem mais à ação do que à reflexão. Para demonstrar sua tese, o crítico cita os longas Relíquia macabra (adaptação do romance $O$ falcão maltês, de Dashiell Hammett) e À beira do abismo (baseado na obra O sono eterno, de Raymond Chandler) como exemplos de grande eficácia visual resultante do gênero inaugurado por Edgar Allan Poe. ${ }^{6}$

Como se vê, estabelecer uma relação entre a obra de Rubem Fonseca inerentemente ligada às tradições realista e detetivesca - e as artes visuais é algo já feito diversas vezes pela crítica. Neste artigo, retomamos o tema e propomos

\footnotetext{
${ }^{5}$ Ibidem, p. 36-37.

${ }^{6}$ Sebastião Uchoa Leite, "As relações duvidosas: notas sobre cinema e literatura", 2003, p. 168169.
} 
uma leitura que, longe de ser original, sugere outra maneira de desfolhar as camadas de um texto literário. Assim, analisamos como a utilização de técnicas narrativas apuradas auxilia nos procedimentos denominados moldura e ekphrasis em A santa de Schöneberg, conto que integra o volume Romance negro e outras histórias. Primeiro, tendo como base passagens retiradas do texto ficcional, tratamos do conceito de moldura; depois, partimos para a ekphrasis, quando se analisa a relação de um personagem com a história do pintor austríaco Egon Schiele. O objetivo é mostrar de que maneira essas representações resultam em uma composição de estética sofisticada, cujo centro é a vida e a obra do pintor Egon Schiele.

\section{Abertura de novas realidades}

A santa de Schöneberg traz uma história envolvendo Ursula e Roberto, dois personagens excêntricos que se conhecem de maneira inusitada. Conduzido por um narrador onisciente, o conto divide-se em pequenos capítulos, cada qual nomeado de acordo com o indivíduo cujo ponto de vista é adotado.

A perspectiva de Ursula é a primeira a ser abordada. De sua janela, ela observa o cômodo em reforma de um edifício localizado em frente ao seu quarto:

Vê do seu quarto a cozinha do apartamento vizinho. Ao fundo há uma porta, que, supõe, deve dar acesso a um corredor; perto dessa porta, uma mesa, de madeira clara, com quatro cadeiras iguais. Vê ainda um fogão de quatro bocas, armários, baixos e altos, pintados de branco; uma geladeira pequena e uma máquina de lavar roupa, do tamanho da geladeira, tudo na cor branca. Sobre os armários baixos, do lado em que fica a geladeira, há uma comprida bancada. A máquina de lavar roupa fica próxima da janela, do lado oposto ao da geladeira, junto a uma pia com duas cubas de aço 
inoxidável. A persiana horizontal dessa janela nunca foi baixada durante as obras que acabaram de ser realizadas naquele apartamento. Agora não mora ninguém ali para fazer isso. $O$ que a atrai naquela cozinha é ela estar sempre vazia. Cozinhas são lugares movimentados, pelo menos as que ela conhece. Quando a obra terminou, alguém deixou a luz acesa e às vezes ela acorda no meio da noite e vai contemplar a cozinha que, emoldurada pela janela e pela escuridão, parece, em sua imobilidade, uma fotografia. ${ }^{7}$

Rosana de Lima Soares escreve que telas e janelas podem ser entendidas como molduras que abrem espaços. Segundo a autora, o termo moldura é adequado tanto para indicar os limites-alcances de uma pintura quanto os alcances-limites da janela, sendo, simultaneamente, contorno e ruptura, algo que define um campo de visão e, consequentemente, deixa de fora outras imagens. ${ }^{8}$

A janela contemplada por Ursula no trecho em destaque funciona como a moldura que cinge uma tela. Na escuridão da noite, a luz deixada acesa exerce contraste que demarca a configuração da cozinha em meio à ausência de luminosidade. Ao mesmo tempo em que são criados contornos limítrofes, abrese um espaço com novo alcance e novas possibilidades de imaginação e de interpretação. Ortega y Gasset ressalta que a obra de arte é uma ilha imaginária rodeada de realidade por todas as partes. Nesse sentido, como se estivesse, à maneira de um quadro, pendurado numa parede escura, o fragmento iluminado desse apartamento é isolado do contexto noturno em que está inserido, resultando noutra representação de realidade que não a penumbra pela qual é rodeado. ${ }^{9}$

\footnotetext{
${ }^{7}$ Rubem Fonseca, Contos reunidos, 1994, p. 645.

${ }^{8}$ Rosana de Lima Soares, “Telas e janelas, molduras das imagens”, 2001, p. 35.

${ }^{9}$ José Ortega y Gasset, “Meditación del marco”, 1963, p. 311.
} 
Como guia descritivo, temos um narrador não participante da história que sumariza pormenorizadamente as cores, nomenclaturas e posições ocupadas no espaço dos móveis que compõem o cenário - tipo de representação realista (como dissemos, ressaltada por Pellegrini), algo também peculiar às histórias de detetive e, consequentemente, à obra de Rubem Fonseca. A onisciência da voz narrativa é revelada quando se alude à suposição, levantada por Ursula, de que a porta localizada no fundo do cômodo leva a algum tipo de passagem, e também no momento em que ela faz menção ao motivo pelo qual se sente atraída por aquele interior: o inusitado fato de, até então, nunca ter visto cozinha com ausência tão grande de movimento. Assim, aquela janela apresenta uma nova interpretação do real, algo que a personagem fonsequiana nunca havia visto.

Os verbos marcados no presente, particularidade que se mantém no decorrer do conto, sugerem a imagem fotográfica que caracterizará cada cena. Susan Sontag afirma que a arte da fotografia apresenta um novo código visual, ampliando e modificando a concepção do que vale a pena ser olhado e observado. ${ }^{10}$ Como a própria narração deixa claro, a inexistência de dinamismo emoldurada pela janela e contemplada por Ursula aproxima o que é descrito da reprodução de uma câmera. Em um mundo visualmente poluído, repleto de ruídos e abarrotado de cozinhas movimentadas, ela descobre a ausência de movimento e seu consequente silêncio, algo pelo qual vale a pena levantar-se no meio da noite e realizar o exercício da contemplação - hábito esquecido na imediata era das redes sociais em que vivemos.

${ }^{10}$ Susan Sontag, "Na caverna de Platão", 2004, p. 13. 
Certo dia, o imóvel é ocupado por um homem. A partir de então, movida por intensa curiosidade, Ursula passa a acompanhar os movimentos de Roberto pelo cômodo:

Hoje, um homem apareceu na cozinha, com uma saca e desapareceu. [...] Ele demora a reaparecer, com um livro debaixo do braço. Ursula não consegue ler o título do livro. O homem olha para a saca, como se fosse um quebra-cabeça. Ursula o observa através do binóculo. Afinal ele retira as mercadorias: oito latas de sopa, não, nove latas de sopa e um pedaço de pão preto envolto em papel celofane, e uma garrafa de vinho tinto. Depois pega a garrafa de vinho e fica olhando para o rótulo. [...] Em seguida, com o livro na mão, sai da cozinha, deixando a luz acesa. [...] O homem nunca toma sopa à mesma hora; nem senta na mesma cadeira, cada vez que sorve a sopa. Às vezes come, junto com a sopa, um pedaço de pão preto. Com um abridor manual retira a tampa da lata, coloca a lata de sopa em uma pequena panela com água, espera a água ferver, tira a lata da panela, põe a lata sobre um prato e toma a sopa diretamente da lata. Ele não deve gostar de lavar louça, provavelmente. ${ }^{11}$

Agora, ao invés de emoldurar imagem estática, a janela se abre para a rotina de Roberto. Rosana de Lima Soares compara a moldura de uma tela - seja ela de pintura ou de cinema - com a opacidade, já que ela devolve ao espectador uma imagem que já é passado. No que diz respeito à janela, a autora associa sua abertura a uma transparência que mostra outra realidade. Em ambos os casos (tela ou transparência), assim como no caso das palavras, há alternância entre velar e revelar um mundo interior/exterior, esteja ele localizado no passado ou no presente. ${ }^{12}$

\footnotetext{
${ }^{11}$ Rubem Fonseca, Op. Cit., 1994, p. 645.

${ }^{12}$ Rosana de Lima Soares, Op. Cit., 2001, p. 35.
} 
No caso de Ursula, a cada dia sua vigília revela detalhes sobre o comportamento de Roberto, sujeito que não possui horário fixo para refeições e que, mesmo morando sozinho, ocupa diferentes lugares à mesa. Há uma personagem de Rubem Fonseca, narradora do conto Fevereiro ou março, que diz:

Ouvi dizer que certas pessoas vivem de acordo com um plano, sabem tudo o que vai acontecer com elas durante os dias, os meses, os anos. Parece que os banqueiros, certos amanuenses de carreira, e outros homens organizados fazem isso. ${ }^{13}$

Roberto certamente não é um desses indivíduos que esquematizam previamente o que será feito de suas vidas. Tal característica não se revela em grandes acontecimentos, mas nas pequenas atitudes cotidianas. Ursula assume o papel da fotógrafa habilidosa que se sente atraída não pelo que está escancarado aos olhos de todos, mas por aquilo que passa despercebido, pela repetição ou variação de ações prosaicas e, para o senso comum, irrelevantes.

Além da predominância dos já mencionados verbos conjugados no presente, outro fator que faz parecer que os eventos ocorrem no momento da leitura é a correção a respeito da quantidade de latas de sopa tiradas da saca e a suposição de que, por ingerir somente alimentos em conserva, Roberto não goste de lavar louça. Nesse ponto, de maneira sutil, vemos o ótimo uso do discurso indireto livre, em que a voz do narrador funde-se com o pensamento da personagem. James Wood escreve sobre um refinamento desse estilo que pode ser chamado de ironia do autor. $O$ distanciamento entre as vozes do escritor e da

\footnotetext{
${ }^{13}$ Rubem Fonseca, Op. Cit., 1994, p. 13.
} 
personagem aparenta desaparecer. Nesse caso, a voz da personagem parece se rebelar e tomar conta da narração. O crítico cita como exemplo um período do conto $O$ violino de Rothschild, de Tchekhov: "A cidade era pequena, pior que aldeia, e habitada só por velhos, que morriam tão raro que isso até causava desgosto". De acordo com Wood, estamos na mente de um fabricante de caixões, para quem a longevidade era um entrevero financeiro. ${ }^{14}$

No conto de Fonseca, a mistura da voz do narrador onisciente com a de Ursula acontece quando há evidência do equívoco cometido (quantidade de latas retiradas da saca) e levantamento de uma hipótese (Roberto evita lavar a louça que se acumula na pia). Adotando as ideias apresentadas por Wood, é como se, nesse momento, Ursula se insurgisse contra o detentor do discurso e tomasse a palavra para si. Assim, temos a certeza de que os fatos narrados, amplificados pelas lentes do binóculo, estão sendo vistos pelos olhos da personagem.

Tal curiosidade transforma-se em obsessão. Fingindo ser candidata a uma vaga de faxineira, a observadora entra no apartamento de Roberto e se depara com o cenário até então visto à distância:

Ali estão as latas de sopa vazias, cada uma com uma colher, as xícaras com tocos de charutos, a garrafa de vinho. [...] Vista de perto a cozinha está ainda mais desarrumada. No ar, um odor forte de charutos. Da janela da cozinha procura localizar a janela do seu quarto. Lá está ela, com as cortinas cerradas; de trás daquelas cortinas ela espia o homem [...]. ${ }^{15}$

\footnotetext{
${ }^{14}$ James Wood, Como funciona a fiç̧ão, 2012, p. 31.

${ }^{15}$ Rubem Fonseca, Op. Cit., 1994, p. 648.
} 
No filme Dreams, de Akira Kurosawa, um pintor percorre um museu com as obras mais famosas de Van Gogh. Em certo momento, ele para diante de uma delas e a contempla. Ludibriado por devaneios e conduzido por sua imaginação, fantasia adentrar o quadro e percorrer caminhos pictóricos. Utilizando as palavras de Ortega y Gasset citadas anteriormente, interage com a ilha imaginária apartada de sua realidade. Da mesma maneira, Ursula invade o espaço até então metonímico, cuja visão era limitada pelo recorte feito pela janela - a diferença entre um caso e outro é que, no conto de Rubem Fonseca, a interação entre personagem e quadro ocorre de modo concreto.

A troca de perspectiva lhe dá novas sensações - o cheiro de charuto, a cozinha com aparência mais caótica do que quando vista ao longe -, nenhuma delas captada de seu quarto, mesmo com a visão aumentada pelo binóculo. Ursula identifica, ainda, a sua própria janela, local de onde espiona Roberto. É como se Jeffries, fotógrafo interpretado por James Stewart no filme Janela indiscreta, de Alfred Hitchcock, assumisse o ponto de vista dos vizinhos que espia, experimentando o efeito de estar na posição daquele que é observado.

Assim como a personagem de Dreams percorre trilhas e campos dentro da pintura de Van Gogh, Ursula explora os cômodos do apartamento. Em uma das paredes, encontra uma reprodução do quadro Sitzende Frau mit hochgezogenem Knie, do pintor austríaco Egon Schiele. Entre as pernas de Edith, companheira do artista e modelo para a feitura da tela, Ursula deixa um bilhete para Roberto. Como veremos, os mistérios envolvendo a vida e a obra de Schiele serão determinantes para o destino daquele homem. 


\title{
3. Três ekphrasis e uma carta
}

Depois de se conhecerem, durante um almoço, Roberto fala sobre uma das obras de Egon:

\begin{abstract}
"Mas é um quadro mais sombrio." Roberto relembra o quadro. Schiele e Edith estão nus. A dele, uma nudez angulosa cheia de arestas, se não fosse o rosto, perplexo, pareceria uma nudez de pedra. A carne maternal do corpo de Edith nada tem do despojamento tranquilo, mas provocante, que as roupas descuidadas não conseguem esconder na Mulher sentada. E no quadro A família, entre as pernas dela, contrastando com a nudez dos pais, vê-se o menino inteiramente vestido, o olhar perdido em algum ponto, como Edith. "Um quadro sombrio", repete Roberto. ${ }^{16}$
\end{abstract}

João Adolfo Hansen escreve que, em exercícios preparatórios de oratória concebidos na Grécia entre os séculos I e IV d. C., ekphrasis remete à descrição ou exposição associadas às técnicas de ampliação de matérias narrativas, nas quais seu autor concebe um narrador que amplifica temas sobre os quais há concordância, como a exaltação da criatividade e do apuro técnico do pintor, além do estilo extraordinário e da beleza da obra de arte em si. ${ }^{17}$

No excerto destacado, ao contrário dos momentos em que Ursula observa a janela vizinha à sua e tem seus pensamentos misturados à voz do narrador, vemos a opinião de Roberto - a respeito do quadro A família - reproduzida por ele próprio, em discurso direto que abre e encerra o parágrafo. Intercalada a reprodução literal de sua fala, temos novamente a onisciência narrativa exercida pelo discurso indireto que decalca o que passa pela cabeça do personagem. Tais

\footnotetext{
${ }^{16}$ Ibidem, p. 652.

${ }^{17}$ João Adolfo Hansen, “Categorias epidíticas da ekphrasis”, 2006, p. 85.
} 
descrições mentais, ao exporem predicativos relacionados à pintura de Schiele, caracterizam a ekphrasis mencionada por Hansen. Misturando sua voz com as lembranças de Roberto, o espectro narrativo sublinha os diferentes tipos de nudez apresentados pelos corpos: a de Schiele, de formas irregulares complementadas pelo rosto pétreo; a de Edith, menos provocante e despojada em comparação a Sitzende Frau mit hochgezogenem Knie, tela em que ela é retratada vestindo curtas e poucas roupas.

A inexistência da sensualidade de outrora leva o personagem a considerar A família um quadro mais sinistro. Passeando por seu pensamento, o narrador de Rubem Fonseca também chama a atenção para o bebê inteiramente vestido e colocado entre as pernas da mãe, contrastando com a nudez dos pais, além de destacar os olhares perdidos da mulher e do menino. Tomando por base uma vez mais as proposições de Hansen anteriormente citadas, ampliam-se, assim, as características relacionadas à técnica do pintor e ao modo como a obra foi concebida.

Como complemento à análise realizada por Roberto e reportada pelo narrador a respeito de A família, há o exame feito por Reinhard Steiner, no qual ele declara tratar-se do último quadro importante do pintor, além de notar a predominância de um fundo sombrio, do qual se destacam tons moderados que, até então, eram desenvolvidos em superfícies coloridas. A ausência de tonalidade mais clara dialoga, segundo o crítico, com a produção do artista nos seus últimos anos de vida. ${ }^{18}$

\footnotetext{
${ }^{18}$ Reinhard Steiner, Egon Schiele: a alma nocturna do artista, 2001, p. 118.
} 
Roberto mostra-se influenciado não só pela arte do retratista austríaco, mas também por seus aspectos biográficos. Durante passagem por Viena, encontra uma carta misteriosa num mercado de pulgas. Mesmo sem abrir o envelope ou ter a confirmação do remetente, ele acredita piamente que ela foi escrita por Schiele, o que lhe desperta um tipo de torpor. Depois de adquirir a missiva, ele pensa em Edith e vai até o museu Belvedere com o intuito de vê-la em A família:

\begin{abstract}
Não é a primeira vez que vê aquele rosto resignado e cheio de compaixão, o corpo curvado com as mãos entre os joelhos. Mas, agora, pensa ver, no olhar da mulher, alguma coisa que nunca notou anteriormente: a figura invisível de Schiele. Não há dúvida de que ela está olhando para o marido - ansiando para que tudo termine logo. E tudo vai mesmo terminar imediatamente, naquele 1918. Mas Roberto agora sabe que existe algo que liga tudo o que aconteceu à carta. Tira a carta do bolso com as mãos trêmulas. Mas não tem coragem de abri-la. ${ }^{19}$
\end{abstract}

Além de associar a ekphrasis ao ato descritivo, Hansen também a relaciona à estruturação de etopeias ${ }^{20}$ - termo que, no Dicionário Houaiss de Língua Portuguesa, é ligado à retórica e definido como descrição literária com especial focalização no temperamento, no caráter, nas paixões e nas tendências de uma ou mais personagens. ${ }^{21}$

No trecho extraído do conto, descrevendo os pensamentos de Roberto e os citando em discurso indireto livre, o narrador apresenta nova leitura das expressões faciais de Edith. Motivado pela descoberta da epístola nunca aberta,

\footnotetext{
${ }^{19}$ Rubem Fonseca, Op. Cit., 1994, p. 655.

${ }^{20}$ João Adolfo Hansen, Op. Cit., 2006, p. 85.

${ }^{21}$ Antônio Houaiss e Mauro de Salles Villar, Dicionário Houaiss da língua portuguesa, 2009, p. 889.
} 
deixa de ver apenas a modelo com olhar perdido, resignado e benevolente. Em seus olhos, enxerga o espectro do marido, objeto capturado pelas órbitas que anseiam pelo término de tudo. A descrição das angústias da figura feminina caracteriza a prática da etopeia destacada por Hansen. Assim, não há somente a ekphrasis de elementos ligados às formas das imagens - como vimos no fragmento em que Roberto reflete sobre a nudez de Edith e Schiele -, mas também a exposição interpretativa daquilo que está implícito.

No ensaio epistolar Cara Giulia, Daniel Arasse critica a atitude de sua interlocutora de utilizar filtros externos (citações, referências, textos) para interpretar obras de arte - o que, para ele, configura um tipo de proteção contra o puro brilho artístico de uma tela. ${ }^{22}$ Pode-se dizer que Roberto, influenciado pela lente extrínseca da mensagem oculta que tem em mãos, adota o mesmo procedimento censurado por Arasse. A nova leitura realizada pelo personagem de A santa de Schöneberg a respeito dos sentimentos obscuros da esposa do pintor está intimamente ligada ao misterioso conteúdo do envelope. Além da carta, há também o filtro influenciador das informações biográficas do artista austríaco. $\mathrm{O}$ desfecho, consumado em 1918 e no qual pensa Roberto, é a morte de Schiele e da esposa. Segundo Reinhard Steiner, acometidos pela gripe espanhola, o casal morreria em outubro daquele ano - uma diferença de apenas setenta e duas horas separa o óbito de um e de outro: ela falece no dia 28; ele, em $31 .{ }^{23}$

O fato é que as informações externas à obra inquietam Roberto, que não tem coragem de violar o lacre do envelope e, ao mesmo tempo, quer saber do que

\footnotetext{
${ }^{22}$ Daniel Arasse, "Cara Giulia”, 2019, p. 7.

${ }^{23}$ Reinhard Steiner, Op. Cit., 2001, p. 121.
} 
trata aquela missiva. Ele resolve ir até o endereço do destinatário, cujo nome é Husack. Centralizada num pátio cercado de antigos edifícios, encontra a santa que nomeia o conto de Rubem Fonseca:

\begin{abstract}
No centro do pátio, entre arbustos, num pedestal de bronze, uma escultura de dois metros de altura, uma mulher que parece ter dezoito anos, vestida com um manto azul drapejado. Ela está dando um passo à frente, o que desnuda, até um pouco acima do joelho, sua perna bem torneada; uma jovem de seios pequenos e rosto rubicundo, mas não querubínico; uma coroa de louros prende seus cabelos; das costas saem-lhe duas asas brancas e ela segura alguma coisa, apoiada sobre o ombro, que Roberto não identifica. ${ }^{24}$
\end{abstract}

Hansen escreve que muitos autores têm como fórmula literária da ekphrasis o escudo de Aquiles, descrito nos versos 483-608 do canto 18 da Ilíada. Porém, o articulista diz que tomar a arma de defesa da personagem homérica como topos esbarra em duas objeções com relação à classificação do que seria ou não ekphrasis: a primeira diz respeito ao fator histórico, já que a narrativa de Homero é muito anterior à criação do termo - sobre esse tópico, Hansen ressalta que, em tempos de desistoricização, qualquer efeito visual pode ser considerado ecfrástico; a segunda, ao não isolamento do objeto descrito em relação à ação épica da história - no caso da Ilíada, a descrição do armamento serve para amplificar a fúria de Aquiles, que sai para vingar a morte de Pátroco, seu irmão. ${ }^{25}$

No trecho destacado, o narrador, adotando a perspectiva de Roberto (algo que pode ser notado no final da passagem, quando há menção de que o

\footnotetext{
${ }^{24}$ Rubem Fonseca, Op. Cit., 1994, p. 656-657.

${ }^{25}$ João Adolfo Hansen, Op. Cit., 2006, p. 87.
} 
personagem não consegue identificar o objeto carregado pela santa), obtém, assim como na descrição do escudo de Aquiles, êxito imagético ao descrever a possível idade da figura feminina, bem como ao expor suas características corporais e das vestimentas que utiliza. Relatando o movimento que descobre uma parte do seu corpo, cria-se também um efeito de narratividade, como se, apesar de estático, ele estivesse se mexendo. Tal detalhamento nos mostra que, ao contrário das formas reproduzidas por Schiele, a jovem de aproximadamente dezoito anos possui contornos torneados e definidos, além de um rosto não querubínico que contrasta com o fato de ostentar asas.

Se Rubem Fonseca, assim como Homero, tem sucesso na criação de efeitos visuais, há ainda a segunda objeção colocada por Hansen, que diz respeito à conexão dos aspectos descritivos com a história. Esse vínculo aparece nos lances finais do conto, quando descobrimos que a estátua colocada entre os prédios da capital austríaca e detalhada pelo narrador será a última coisa vista por Roberto antes de morrer.

Ao tocar a campainha de um dos edifícios, este é recebido por um homem chamado Schlüter, que o leva até o apartamento de Husack - sujeito em idade avançada, preso a uma cadeira de rodas e amparado por uma provável enfermeira. A ele, o brasileiro entrega a carta. Depois de verificar que ela não havia sido aberta, o idoso pergunta quanto o desconhecido quer pelo documento. A resposta não vem na forma de dinheiro, mas de questionamento - Roberto deseja saber se a missiva tem relação com Schiele: 


\begin{abstract}
"Sim, sim, você sabe que sim!" Husack curva o corpo como se esvaziado e estripado subitamente de suas vísceras, encosta o rosto nos joelhos. "O que você sabe sobre Schiele? Meu Deus, quando poderei esquecer o passado?", murmura, com palavras quase inaudíveis.

$[\ldots]$

"E eu? O que eu tenho a ver com isso tudo?", pergunta Roberto.

"Seu tolo, você não sabe?", diz a mulher.

"Ele não sabe", diz Husack tristemente.

Neste instante, Schlüter, num movimento rápido, passa um cordão grosso em volta do pescoço de Roberto. Os dois começam a lutar. Em busca de ar, Roberto cambaleia em direção à luz rósea-violeta que entra pela janela. A madeira velha e os vidros cedem com estrépito.

Schlüter é arrastado por Roberto na queda. Os prédios em torno da santa de Schöneberg parecem rodar. A santa também gira, se aproxima rapidamente, e se apaga. ${ }^{26}$
\end{abstract}

Ricardo Piglia afirma que o conto narra duas histórias - uma aparente, outra secreta - e divide os relatos breves em clássico e moderno. A respeito do relato clássico, Piglia diz que o contista codifica a história secreta entre as fendas do relato aparente, produzindo o efeito de surpresa no final, momento em que a narração cifrada vem à superfície. Com relação ao moderno, o crítico ressalta que as duas histórias são contadas como se fossem apenas uma e o escritor manipula a tensão entre elas sem nunca a resolver; ao final, o artista aplica a teoria do iceberg hemingwayana, em que o mais importante nunca é contado. ${ }^{27}$

Para que o raciocínio do escritor argentino fique mais claro, tomemos como exemplo Assassinatos na Rua Morgue, de Edgar Allan Poe, considerado pela maioria dos estudiosos do romance policial como o primeiro espécime desse tipo de narrativa. Narradas em forma de memórias, as duas histórias mencionadas por Piglia, ali, são a do crime e a da investigação. Os assassinatos citados no título

\footnotetext{
${ }^{26}$ Rubem Fonseca, Op. Cit., 1994, p. 659.

${ }^{27}$ Ricardo Piglia, Formas breves, 2004, p. 91-92.
} 
se referem à misteriosa carnificina envolvendo duas mulheres, mãe e filha, moradoras de um conjunto habitacional localizado no subúrbio de Paris. Quando C. A. Dupin (tido como protótipo dos detetives que viriam a seguir) fica sabendo do caso por meio dos jornais, inicia um solitário inquérito que habita a superfície do texto. O leitor acompanha a maneira como o detetive amador visita o local do crime e averigua todas as marcas deixadas pelo apartamento. Ao final, como se resolvesse uma equação matemática, sem deixar pontas soltas, Dupin demonstra de que maneira o delito foi praticado (segunda história) e apresenta as conclusões às quais chegou, caracterizando o desfecho de um conto clássico.

Metáfora da geleira imaginada por Hemingway, a variante moderna dessa forma de narrativa pode ser exemplificada por um conto do próprio autor. Os pistoleiros nos conta sobre um homem que recebe a notícia de que está prestes a ser assassinado por dois sujeitos. Inexplicavelmente, mesmo sabendo do perigo que o cerca, ele aceita seu destino. Terminada a leitura da última página, a narrativa que elucidaria o motivo de sua decisão suicida permanece codificada, sem solução.

Se o conto de Rubem Fonseca seguisse a linha clássica das formas breves cujos maiores representantes, segundo Piglia, são Quiroga e $\mathrm{Poe}^{28}$-, provavelmente o envelope seria aberto e saberíamos qual a gravidade dos fatos ali descritos. Lendo o excerto em destaque, percebe-se que a carta esconde alguma coisa de muito grave a respeito do passado de Egon Schiele e de Husack, algo que pode ser notado pela atitude do idoso ao perguntar o que Roberto sabe sobre o pintor - curvando-se sobre os joelhos como se sentisse forte dor, ele

${ }^{28}$ Ibidem, p. 91. 
evidencia que os acontecimentos pretéritos ainda lhe afetam. Porém, esses fantasmas não são revelados, bem como a relação de Roberto com esse mistério; informação que, exceto ele próprio, todos naquela sala demonstram saber. Por manter o conteúdo da epístola oculto, a narrativa fonsequiana enquadra-se no modelo cujo modus operandi é a metaforização do iceberg associada ao autor de $O$ velho e o mar: vemos somente sua ponta na superfície do texto e temos vaga noção do que pode estar abaixo dessa linha.

Diferentemente da maioria dos fragmentos analisados, na passagem em questão há quase que a predominância do discurso direto, o narrador delegando a cada personagem sua própria voz. Somente no final é que ele volta a adotar a onisciência, descrevendo a visão rodopiante dos edifícios tida por Roberto ao precipitar-se pela janela, moldura da qual vaza luminosidade em tons rosa e violeta. Retomando as ideias de Rosana de Lima Soares, ao estilhaçar a barreira de vidro que separa o mundo exterior do cômodo fechado, é como se o personagem (que leva consigo seu oponente) rompesse os alcances-limites de sua moldura, mergulhando em imagens que, graças ao contorno da janela, eram deixadas fora do seu campo de visão. Em queda livre, ele vê tudo girar, inclusive a estátua da santa que observara momentos antes e com a qual colide antes de perder a consciência, consolidando o vínculo, mencionado por Hansen, entre o objeto descrito e a narração. 


\section{Considerações finais}

Resgatando as análises realizadas neste trabalho, é possível fazer um levantamento dos resultados e refletir sobre eles em novo exame. Podemos considerar, de maneira sucinta, como Rubem Fonseca apropria-se habilmente de recursos narrativos para a construção de molduras e a realização da ekphrasis.

Ao investigarmos a caracterização do que se tem por moldura, observamos como o narrador onisciente, adotando a perspectiva de Ursula, faz da janela vizinha ao apartamento da personagem o recorte para uma nova representação da realidade. Esse quadro, posicionado em meio a tantas outras possibilidades espaciais, revela uma imagem congelada e, depois, o cotidiano de um homem que se alimenta apenas de sopas enlatadas, como se a personagem observadora assistisse a um filme mudo. Porém, em ações tão prosaicas, ela enxerga um indivíduo dominado por angústias e inquietudes que, possivelmente, se veem refletidas nas telas de Egon Schiele. Além disso, há a mudança de perspectiva no momento em que ela invade o cenário outrora limitado pelas bordas da abertura, o que lhe dá a possibilidade de assumir a posição do objeto contemplado.

O mesmo narrador, alternando, em alguns momentos, o uso do discurso indireto livre com a aplicação do discurso direto, misturando sua voz aos pensamentos de Roberto, realiza o que Hansen entende por ekphrasis - não apenas no que diz respeito à pura descrição de formas, mas também com relação à interpretação de possíveis sentimentos ocultos (presentes nas expressões das figuras retratadas por Schiele no quadro A família). Além disso, Rubem Fonseca consegue conectar a descrição da imagem que dá nome à narrativa com o papel que ela teria no destino (trágico?) de Roberto. 
Esse ponto, aliás, traz à tona uma questão: pelo que analisamos até aqui, é notório que A santa de Schöneberg é mais uma prova da habilidade narrativa de um escritor consagrado. Mas como tirar, de um conto dedicado a descrições visuais, uma trama? O autor mostra que consegue realizar tal tarefa ao inserir o mistério envolvendo a carta encontrada no mercado de pulgas vienense.

Antoine Compagnon, recorrendo ao historiador italiano Carlo Ginzburg, compara o leitor ao detetive, ou seja, um caçador em busca de indícios que possibilitem dar sentido à história. Opondo-se à dedução, o padrão desse tipo de conhecimento é a arte do caçador, que decodifica a narrativa do caminho feito pelo animal a partir das pegadas deixadas por ele. A reconstituição dessa sequência pode levar a uma identificação baseada em vestígios quase invisíveis. ${ }^{29}$

Assim como esse caçador da pré-história, Roberto lê marcas, indícios que o instigam a realizar possíveis outras leituras, a fazer interpretações que vão além do que está na superfície dos quadros. A missiva e o seu misterioso conteúdo relacionado à vida de Schiele se apresentam como sinais deixados pelo artista, para que seu espectador aficionado tente decodificar sentimentos e significados escondidos nos mínimos detalhes de sua obra - aquilo que, dentro dos estudos sobre ekphrasis, Hansen define como etopeia.

No caso do personagem fonsequiano, o documento serve para que ele encontre nos olhos de Edith algo que ainda não havia visto, mesmo tendo olhado para aquela imagem inúmeras vezes. Porém, ao chegar muito perto do segredo guardado pela carta e refletido em A família, Roberto tem sua existência brutal e

\footnotetext{
${ }^{29}$ Antoine Compagnon, O demônio da teoria: literatura e senso comum, 2010, p. 129.
} 
abruptamente aniquilada. Apesar da morte violenta, não é a mesma violência espetacularizada de contos como Feliz ano novo e Passeio noturno, cujos assassinatos são descritos detalhadamente, com requintes de crueldade. Em $\mathrm{A}$ santa de Schöneberg, a perda de consciência do protagonista, que encerra a narrativa, é relatada de maneira fragmentada. A imagem da jovem estátua, que dá nome à história e que teve as formas analisadas por Roberto, se torna sua última visão. Um amante da arte que morre pela arte.

A mensagem cifrada no envelope de Schiele também se conecta à arte do conto moderno destacada por Piglia. À maneira do pintor austríaco, Rubem Fonseca codifica uma segunda história sob a superfície ao mesmo tempo límpida e opaca de seu texto, trama secreta que nem seu habilidoso narrador onisciente é capaz de revelar. Acompanhamos a trajetória inquieta de um homem até seu destino final, mas não sabemos o que foi realmente determinante para sua morte.

Cabe a nós, leitores, adotando a mesma atitude de Roberto com relação à arte de Schiele, retornarmos à obra de Rubem Fonseca e, munidos de filtros externos ou não, desfolharmos o texto literário de diferentes maneiras a cada nova leitura - até que cheguemos tão perto da segunda história que nosso algoz não terá alternativa senão nos atirar pela janela.

\section{Referências}

ARASSE, Daniel. Cara Giulia. In: ARASSE, Daniel. Nada se vê: seis ensaios sobre pintura. São Paulo: Editora 34, 2019. p. 7-21. 
COMPAGNON, Antoine. O demônio da teoria: literatura e senso comum. Belo Horizonte: Editora UFMG, 2010.

FONSECA, Rubem. Contos reunidos. São Paulo: Companhia das Letras, 1994. GENETTE, Gérard. Discurso da narrativa. Lisboa: Vega, [197-].

HANSEN, João Adolfo. Categorias epidíticas da ekphrasis. Revista USP, São Paulo, n. 71, p. 85-105, nov. 2006.

HEMINGWAY, Ernest. Contos de Hemingway: volume 2. Rio de Janeiro: Bertrand Brasil, 2006.

HOUAISS, Antônio; VILLAR, Mauro de Salles. Dicionário Houaiss da língua portuguesa. Rio de Janeiro: Objetiva, 2009.

LEITE, Sebastião Uchoa. As relações duvidosas: notas sobre cinema e literatura. In: LEITE, Sebastião Uchoa. Crítica de ouvido. São Paulo: Cosac \& Naify, 2003. p. 143-173.

ORTEGA Y GASSET, José. Meditación del marco. In: ORTEGA Y GASSET, José. Obras Completas - El espectador (1916-1934). Madrid: Revista de Occidente, 1963. p. 307-313, tomo II.

PELLEGRINI, Tânia. Rubem Fonseca. In: PELLEGRINI, Tânia. A imagem e a letra: aspectos da ficção brasileira contemporânea. Campinas: Mercado de Letras; São Paulo: Fapesp, 1999. p. 80-105.

PETRIK, Tiago; PORTO, Malu; LIMA, João Gabriel de. O personagem Rubem Fonseca. Bravo!, São Paulo, n. 147, p. 30-41, nov. 2009.

PIGLIA, Ricardo. Formas breves. São Paulo: Companhia das Letras, 2004. 
POE, Edgar Allan. Assassinatos na Rua Morgue e outras histórias. Porto Alegre: L\&PM, 2009.

SOARES, Rosana de Lima. Telas e janelas, molduras das imagens. Significação:

Revista de Cultura Audiovisual, v. 28, n. 16, p. 31-44, nov. 2001.

SONTAG, Susan. Na caverna de Platão. In: SONTAG, Susan. Sobre fotografia. São Paulo: Companhia das Letras, 2004. p. 11-35.

STEINER, Reinhard. Egon Schiele: a alma nocturna do artista. Lisboa: Taschen, 2001.

VIDAL, Ariovaldo José. Roteiro para um narrador: uma leitura dos contos de Rubem Fonseca. Cotia: Ateliê Cultural, 2000.

WOOD, James. Como funciona a ficção. São Paulo: Cosac \& Naify, 2012.

\section{Referência para citação deste artigo}

DOS REIS, Murilo Eduardo. Rubem Fonseca: da moldura à ekphrasis. Revista PHILIA | Filosofia, Literatura \& Arte, Porto Alegre, volume 2, número 1, p. 438 - 461, junho de 2020. 